\title{
Wettability alteration by magnesium ion binding in heavy oil/brine/chemical/sand systems-analysis of hydration forces
}

\author{
Qiang Liu ${ }^{1}$, Ming-Zhe Dong ${ }^{2}$, Koorosh Asghari ${ }^{1}$, Yun Tu$^{3}$ \\ ${ }^{1}$ Faculty of Engineering, University of Regina, Regina, Canada; \\ ${ }^{2}$ Department of Chemical and Petroleum Engineering, University of Calgary, Calgary, Canada; \\ *Corresponding Author: mingzhe.dong@ucalgary.ca \\ ${ }^{3}$ Institute for Chemical Process and Environmental Technology, National Research Council, Ottawa, Canada
}

Received 17 November 2009; revised 13 January 2010; accepted 28 February 2010.

\begin{abstract}
In laboratory sandpack tests for heavy oil recovery by alkaline flooding, it was found that wettability alteration of the sand had a significant impact on oil recovery. In this work, a heavy oil of $14^{\circ} \mathrm{API}$ was used to examine the effect of organic acids in the oil and water chemistry on wettability alteration. From interfacial tension measurements and sand surface composition analysis, it was concluded that the water-wet sand became preferentially oil-wet by magnesium ion binding. The presence of $\mathrm{Mg}^{2+}$ in the heavy oil/ $\mathrm{Na}_{2} \mathrm{CO}_{3}$ solution/sand system increased the oil/water interfacial tension. This confirmed the hypothesis that magnesium ion combined with the ionized organic acids to form magnesium soap at oil/water interface. Under alkaline condition, the ionized organic acids in the oil phase partition into the water phase and subsequently adsorb on the sand surfaces. The analysis of sand surface composition suggested that more ionized organic acids adsorbed on the sand surface through magnesium ion binding. The attachment of more organic acids on the sand surface changed hydration forces, making the sand surface more oil-wet.
\end{abstract}

Keywords: Wettability Alteration; Alkaline Flooding; Magnesium Ion Binding; Interfacial Tension;

Organic Acids

\section{INTRODUCTION}

Wettability plays an important role in determining the distribution and flow of fluids in the pores of a reservoir [1]. Whether the pore surface of reservoir rock is water- wet or oil-wet is determined by the thickness of the water film between the rock surface and the oil [2]. For very thick films, the system is stable and remains waterwet. If it is unstable, the film will break, resulting in direct contact of oil to the rock surface and adsorption of polar components on pore walls. The stability of a thick water film is dependent on the magnitude of the disjoining pressure. The disjoining pressure that tends to disjoin or separate the oil/water and water/rock interfaces are identified as a combination of van der Waals, electrostatic and hydration forces. The van der Waals forces are attractive, while electrostatic forces are repulsive between the interfaces. The hydration forces can be either a hydrophilic effect for a surface such as clean quartz or a hydrophobic effect for a surface with an organic coating. If the magnitude of repulsive forces is greater than the attractive forces, the water film is stable, and the surface remains water-wet.

The hydrophobic effect of hydration forces can be caused by the adsorption of polar compounds that were originally in crude oils [3-5]. These compounds have a polar end and a hydrocarbon chain. The polar end contacts the rock surface and the hydrocarbon chain exposes to the liquid phase, making the surface more oil-wet [6]. Some of the polar compounds are soluble in water so that they can diffuse through the thin water film to adsorb onto the rock surface [7]. It has been found that, even when a surface active compound has a very low solubility in water, it could reach the solid surface by diffusion through the water film [8]. This will make the attractive force greater and the water film could be drained to result in an oil-wet surface.

Kowalewski et al. [9] conducted wettability tests using Berea sandstone, brine $(\mathrm{NaCl})$ and $n$-decane with different concentrations of hexadecylamine. The wettability of the sandstone samples was changed from water-wet to neutral due to the adsorption of hexadecylamine on the rock surface. Ashayer et al. [10] studied 
the influence of surfactant molecules (alkyl ether carboxylic acid) on wetting phenomena with a glass micromodel. It has been found that the solid surface attracts the polar head group of the surfactant molecules and the tail of the surfactant is free at the water/glass interface. The attractive force between the hydrophobic tail of the surfactant and the oil chain causes the formation of a "hydrophobic bond", which changes the wettability of the surface from water-wet to oil-wet. Buckley et al. [11] believed that when the brine phase contained divalent cations, wettability could be altered by ion binding mechanism. The divalent ions combined the oil with mineral surface, making the mineral less water-wet.

Wettability alteration is one of the mechanisms of enhanced oil recovery by alkaline flooding. Cooke et al. [12] studied wettability in alkaline flooding in glass micro-model by acidic oils and formation waters. They observed that the wettability of the matrix of the glass micro-model changed from strongly water-wet to preferentially oil-wet after alkaline flooding. They believed that the wettability alteration was caused by the adsorption of ionized acids onto the solid surface.

Waterflooding of heavy oil reservoirs exhibits very poor sweep efficiency mainly due to a adverse mobility ratio and water channeling [13]. Ma et al. [14] conducted channeled sandpack flood tests of alkaline flooding for a Western Canadian heavy oil sample. It was found that wettability alteration of sand led to oil re-distribution, blockage of existing water channel in porous media and improvement in oil recovery. Liu et al. [15] studied wettability alteration in a heavy oil/water/sand system by analyzing the electronic forces at oil-water and watersand interfaces through $\zeta$-potential measurements. They found that the presence of either $\mathrm{Na}_{2} \mathrm{CO}_{3}$ or $\mathrm{Mg}^{2+}$ alone in the water phase could not induce wettability alteration. When the water phase contained both $\mathrm{Na}_{2} \mathrm{CO}_{3}$ and $\mathrm{Mg}^{2+}$, the water-wet sand became preferentially oil-wet by magnesium ion binding. The reduction in zeta $(\zeta)$-potential at both oil-water and water-sand interfaces due to the addition of $\mathrm{Mg}^{2+}$ to the heavy oil $/ \mathrm{Na}_{2} \mathrm{CO}_{3}$ solution/sand system confirmed the combination of $\mathrm{Mg}^{2+}$ and ionized organic acids at the oil/water interface. They concluded that the reduction of repulsive electrostatic forces between oil drops and sand surfaces contributed to the wettability change of the sand from water-wet to oil-wet.

The objective of this paper is to examine the contribution of hydration forces at oil-water interface to the wettability alteration in the heavy oil/water/sand system used by Liu et al. [15]. The magnesium ion binding was investigated by measuring oil-water interfacial tension (IFT) and water surface tension and analyzing sand surface composition. These results provide insight into the partition of polar compounds in heavy oil/water system and their adsorption onto the sand surface as well as the relation between the magnesium ion binding and wettability alteration.

\section{EXPERIMENTAL}

In this study, micro-slide and micro-model tests were conducted to observe wettability alteration during the oil displacement process. Heavy oil/brine interfacial tensions and surface tension of water phase were measured for different systems to investigate the interactions between heavy oil, brine and sand. Sand surface compositions under different conditions were analyzed to evaluate the adsorption of polar substances onto sand surface after oil/water/sand interaction. All tests were conducted at ambient temperature $\left(22 \pm 0.5^{\circ} \mathrm{C}\right)$ except specified.

\subsection{Materials}

A heavy oil of $14^{\circ} \mathrm{API}$ collected from a reservoir in Alberta, Canada was used in this study. The oil sample was centrifuged at $10,000 \mathrm{rpm}$ at $35^{\circ} \mathrm{C}$ for two hours to remove water and solids. The viscosity, density and acid numbers of the oil were analyzed and are shown in Table 1 . The oil had a viscosity of $1,800 \mathrm{mPa} \cdot \mathrm{s}$ and a density of $0.964 \mathrm{~g} / \mathrm{cm}^{3}$ at $22^{\circ} \mathrm{C}$.

In this study, the effect of divalent ions (mainly $\mathrm{Ca}^{2+}$ and $\mathrm{Mg}^{2+}$ ) on the wettability of the sand in oil/brine/sand system was examined. Solution of $1.0 \mathrm{wt} \% \mathrm{NaCl}$ in deionized water other than the formation brine was used as water phase for the anaysis of hydration forces [15]. $\mathrm{MgCl}_{2}$ was added to adjust $\mathrm{Mg}^{2+}$ concentration in water phase. $\mathrm{Na}_{2} \mathrm{CO}_{3}$ was used to neutralize the organic acids (polar compounds) in the oil.

Varsol (a commercial solvent containing kerosene as the main component) and ethanol were used to clean the micromodel. The sand used in this work was from U.S. Silica Company and was originally water-wet.

\subsection{Wettability Tests with Micro-Slide and Micro-Model}

In this paper, two methods are employed to examine the wettability of a solid surface in porous media: micro-slide test and micro-model test. For the details of the micro-slide and micro-model tests, readers are referred to a previous work by Liu et al. [15].

Micro-slide tests were conducted for observing the wettability of sands in different oil/alkaline solution systems. The oil and water were equilibrated for 50 hours

Table 1. Viscosity, density and acid number of the heavy oil sample.

\begin{tabular}{ccccc}
\hline \multirow{2}{*}{$\begin{array}{c}\text { Viscosity, } \\
\mathrm{mPa} \cdot \mathrm{s}\end{array}$} & $\begin{array}{c}\text { Density, } \\
\mathrm{g} / \mathrm{cm}^{3}\end{array}$ & \multicolumn{3}{c}{$\begin{array}{c}\text { Acid number, mg KOH per gram of } \\
\text { sample }\end{array}$} \\
\cline { 3 - 5 } & 0.964 & Strong & Weak & Total \\
\hline 1,800 & 0.89 & 0.43 & 1.32 \\
\hline
\end{tabular}


and separated for micro-slide tests. Sand was added into the water phase for adsorption for 50 hours and separated for preparing the micro-slide models. Then a monolayer of the sand was sandwiched between two micro-slides and saturated with the equilibrium oil phase. The equilibrium water phase was introduced to the model for an imbibition-type displacement of oil.

A glass micro-model was used to conduct alkaline flooding. The transparent nature of the micro-model allows the pore-scale multi-phase displacement and wettability of the pore surfaces to be visually observed [16]. The displacement procedure for a micro-model test was as follows:

1) Saturate the micromodel with the water phase (1.0 wt $\% \mathrm{NaCl}$;

2) Inject the heavy oil or kerosene;

3) Conduct waterflood $(1.0 \mathrm{wt} \% \mathrm{NaCl})$ for two pore volumes (PV);

4) Conduct alkaline flood by injecting $0.20 \mathrm{wt} \%$ $\mathrm{Na}_{2} \mathrm{CO}_{3}$ in brine with or without $\mathrm{Mg}^{2+}$ for one PV.

Microphotographs were taken at different stages of the displacement tests to observe the wettability of the pore surface.

\subsection{IFT Measurement}

The spinning drop tensiometer (Model 510, Temco, USA) was employed to measure the water surface tension and oil/water interfacial tension. For surface tension measurement, an air bubble was injected into a glass tube filled with a water solution; for IFT measurement, an oil droplet was injected into the glass capillary tube. The IFTs and surface tensions are determined using the following equation:

$$
\sigma=3.42694 \times 10^{-7}\left(\rho_{h}-\rho_{d}\right) \omega^{2} D^{3} \quad \mathrm{~L} / \mathrm{D} \geq 4
$$

where $\sigma$ is interfacial tension (dyne/cm), $\rho_{h}$ is the density of heavy (outer) phase $\left(\mathrm{g} / \mathrm{cm}^{3}\right), \rho_{d}$ is the density of light (drop) phase $\left(\mathrm{g} / \mathrm{cm}^{3}\right), \omega$ is rotational velocity $(\mathrm{rpm}), D$ is measured drop width (diameter) $(\mathrm{mm})$, and $\mathrm{L}$ is the length of the oil drop (mm).

\subsection{Analysis of Sand Surface Composition}

In the heavy oil/brine/sand systems, some of the ionized organic acids in the oil phase will partition into the water phase and subsequently adsorb on the sand surface. The adsorption of ionized organic acids on the sand surface was investigated by analyzing the surface compositions of the sand before and after it was brought to contact the water phase. Because the sand surface was easily contaminated by oil drops in the water phase, the sand was equilibrated with the heavy oil/brine system as follows. 1) The water phase was equilibrated with the heavy oil; 2) The water phase was filtered to remove oil droplets before it was mixed with the sand; 3) The sand sample was mixed with the water phase for two weeks for ad- sorption; 4) The sand was separated from the water using a stainless steel sieve and dried in an oven at $60^{\circ} \mathrm{C}$ for one hour. The compositions of the top 7-nm surface layer of the sand was analyzed by using a Kratos AXIS Ultra X-Ray photoelectron spectrometer (XPS), equipped with a hemispherical analyzer, a delay line detector, charge neutralizer and monochromated $\mathrm{Al} \mathrm{K \alpha} \mathrm{X}$-ray source.

\section{RESULTS AND DISCUSSION}

\subsection{Onset $\mathrm{Na}_{2} \mathrm{CO}_{3}$ and $\mathrm{Mg}^{2+}$ Concentrations for Wettability Alteration}

In the previous wettability study by Liu et al. [15], the heavy oil was equilibrated with water phases of different compositions by adding $\mathrm{Na}_{2} \mathrm{CO}_{3}$ or $\mathrm{NaOH}$ to react with the organic acids in the oil and $\mathrm{CaCl}_{2}$ and $\mathrm{MgCl}_{2}$ to adjust $\mathrm{Ca}^{2+}$ or $\mathrm{Mg}^{2+}$ in the water phase. It was found that the presence of $\mathrm{Na}_{2} \mathrm{CO}_{3}$ and $\mathrm{Mg}^{2+}$ could cause wettability alteration in the heavy oil/water/sand systems. In order to examine the effect of $\mathrm{Na}_{2} \mathrm{CO}_{3}$ and $\mathrm{Mg}^{2+}$ on wettability alteration, micro-slide tests were conducted with various $\mathrm{Na}_{2} \mathrm{CO}_{3}$ and $\mathrm{Mg}^{2+}$ concentrations.

Table 2 shows the results of micro-slide tests at different $\mathrm{Na}_{2} \mathrm{CO}_{3}$ concentrations with or without the presence of $\mathrm{Mg}^{2+}$. No wettability alteration was observed for the samples of Series A, which contained only $\mathrm{Na}_{2} \mathrm{CO}_{3}$. In the presence of $100 \mathrm{mg} / \mathrm{L} \mathrm{Mg}^{2+}$, wettability alteration occurred when $\mathrm{Na}_{2} \mathrm{CO}_{3}$ concentration reached a specific value; $0.10 \mathrm{wt} \%$ for Series B in which $100 \mathrm{mg} / \mathrm{L} \mathrm{Mg}^{2+}$ was added after the water phase was equilibrated with the oil; $0.20 \mathrm{wt} \%$ for Series $\mathrm{C}$ in which $100 \mathrm{mg} / \mathrm{L} \mathrm{Mg}^{2+}$ was added before the water phase was equilibrated with the oil.

The onset $\mathrm{Mg}^{2+}$ concentration for wettability alteration was investigated by using micro-slide tests with 0.20 wt $\% \quad \mathrm{Na}_{2} \mathrm{CO}_{3}$ and various $\mathrm{Mg}^{2+}$ concentrations (named as Series $D$ in Table 3). Magnesium ions were added into the water phase before oil-water equilibration. As shown in Table $\mathbf{3}$, wettability alteration was initiated at a concentration of $50 \mathrm{mg} / \mathrm{L} \mathrm{Mg}^{2+}$.

\subsection{Effect of Organic Acids on Wettability Alteration}

To investigate the effect of organic acids in oil on wettability alteration, two micro-model tests were conducted to observe wettability alteration during alkaline flooding displacement. In one test, the heavy oil was used; in the other test, kerosene was used as the oil phase which was free of organic acids. The same water phase (1.0 $\mathrm{wt} \%$ $\mathrm{NaCl}+0.20 \mathrm{wt} \% \mathrm{Na}_{2} \mathrm{CO}_{3}+100 \mathrm{mg} / \mathrm{L} \mathrm{Mg}^{2+}$ ) was used for both tests.

Figure 1 shows the pore-level microphotographs of the micro-model taken during the test with the heavy oil, 
Table 2. Wettability of sand in micro-slide tests at different $\mathrm{Na}_{2} \mathrm{CO}_{3}$ concentration with or without the presence of $\mathrm{Mg}^{2+}$.

\begin{tabular}{|c|c|c|c|c|c|c|}
\hline \multirow{2}{*}{ Test series } & \multirow{2}{*}{ Method of $\mathrm{Mg}^{2+}$ addition } & \multicolumn{5}{|c|}{$\mathrm{Na}_{2} \mathrm{CO}_{3}$ concentration, $\mathrm{wt} \%$} \\
\hline & & 0.020 & 0.050 & 0.10 & 0.20 & 0.50 \\
\hline A & $\mathrm{No} \mathrm{Mg}^{2+}$ & No & No & No & No & No \\
\hline B & $100 \mathrm{mg} / \mathrm{L} \mathrm{Mg}^{2+}$ added after water equilibrated with oil & No & No & Yes & Yes & Yes \\
\hline $\mathrm{C}$ & $100 \mathrm{mg} / \mathrm{L} \mathrm{Mg}^{2+}$ added before water equilibrated with oil & No & No & Partial & Yes & Yes \\
\hline
\end{tabular}

Note: Yes-wettability alteration; No-no wettability alteration; Partial-partial wettability alteration.

Table 3. Effect of $\mathrm{Mg}^{2+}$ on wettability in micro-slide tests, $\mathrm{Na}_{2} \mathrm{CO}_{3}: 0.20 \mathrm{wt} \%$ (Test series D).

\begin{tabular}{lllllll}
\hline Concentration of $\mathrm{Mg} 2+, \mathrm{mg} / \mathrm{L}$ & 0 & 10 & 20 & 50 & 100 & 200 \\
\hline Wettability alteration & No & No & No & Yes & Yes & Yes \\
\hline
\end{tabular}

showing oil and water distribution at different displacement stages. Water films between the oil and the pore walls exist before the injection of alkaline solution. After alkaline flooding, oil films exist between the water and pore walls, indicating that the pore walls have became preferentially oil-wet. The oil/water menisci in Figures 1(b) to 1(d) are convex to the oil phase, suggesting that the glass pore is oil-wet. It is also shown from the distribution of oil and water phase in the pores that the glass model has become preferentially oil-wet. The results in Figure 1 are consistent with those in micro-slide tests.

Figure 2 shows the wettability of glass pores at different stages of the micro-model test with kerosene. The glass pores remained water-wet after alkaline flooding. The difference between crude oil and kerosene is that the heavy oil contains organic acids and kerosene does not. The results of the two micro-model tests suggest that the organic acids in the oil phase are the origin of wettability alteration in alkaline flooding.

\subsection{Heavy Oil/Brine/Sand Interactions}

As reviewed in the introduction, hydration forces can have a hydrophobic effect for a surface with an organic coating. In this section, the effect of heavy oil/brine/sand interaction on the hydration forces is investigated. The samples of Series A through D listed in Tables 2 and $\mathbf{3}$ were used for the following measurements and tests.

\subsubsection{IFT Variation Caused by the Presence of $\mathrm{Mg}^{2+}$}

The combination of magnesium and ionized organic acids deactivate the ionized acids at the oil/water interface and, therefore, increases the oil/water interfacial tension. To see the interaction of $\mathrm{Mg}^{2+}$ and ionized organic acids at oil/water interface, interfacial tensions of the heavy oil and water phase were measured for systems with and without $\mathrm{Mg}^{2+}$. Figure 3 shows the interfacial tensions as a function of $\mathrm{Na}_{2} \mathrm{CO}_{3}$ concentration for two water solutions: one did not contain $\mathrm{Mg}^{2+}$ and the other contained $20 \mathrm{mg} / \mathrm{L} \mathrm{Mg}^{2+}$. The addition of $\mathrm{Na}_{2} \mathrm{CO}_{3}$ in the water phase reduced the IFT of the heavy oil and water from its original value (approximately $25 \mathrm{dyne} / \mathrm{cm}$ ) to $2.13,1.12$, and $0.38 \mathrm{dyne} / \mathrm{cm}$ at $0.02,0.05$, and 0.1 $\mathrm{wt} \% \mathrm{Na}_{2} \mathrm{CO}_{3}$, respectively. In the presence of $20 \mathrm{ml} / \mathrm{L}$ $\mathrm{Mg}^{2+}$, the IFTs were raised to $12.0,7.5$, and 4.5 at the above three $\mathrm{Na}_{2} \mathrm{CO}_{3}$ concentrations, respectively, and to approximately one order magnitude higher at $\mathrm{Na}_{2} \mathrm{CO}_{3}$ concentrations between 0.1 and 0.5 wt $\%$. Figure 4 shows the IFT of the heavy oil and brine at $0.20 \mathrm{wt} \%$ $\mathrm{Na}_{2} \mathrm{CO}_{3}$ and different $\mathrm{Mg}^{2+}$ concentrations. The IFT was increased dramatically with $\mathrm{Mg}^{2+}$ concentration between 0 to $20 \mathrm{mg} / \mathrm{L}$ and then increased slightly with $\mathrm{Mg}^{2+}$ concentration in the water phase. This indicates that the surface activity of the ionized organic acids was decreased significantly by the presence of $\mathrm{Mg}^{2+}$. The divalent cation, $\mathrm{Mg}^{2+}$, could be concentrated at the oil/water interface; therefore, only $20 \mathrm{mg} / \mathrm{L} \mathrm{Mg}^{2+}$ could make the ionized organic acids incapable in reducing the IFT between the oil and water.

The dynamic IFTs of the heavy oil with three water samples of Series D $\left(0,5\right.$, and $\left.10 \mathrm{mg} / \mathrm{L} \mathrm{Mg}^{2+}\right)$ were also

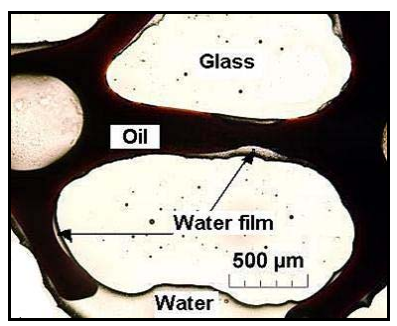

(a)

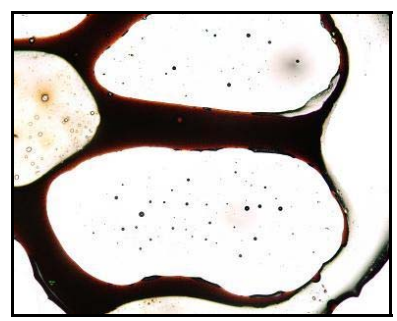

(c)

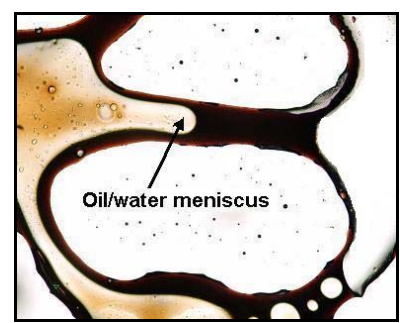

(b)

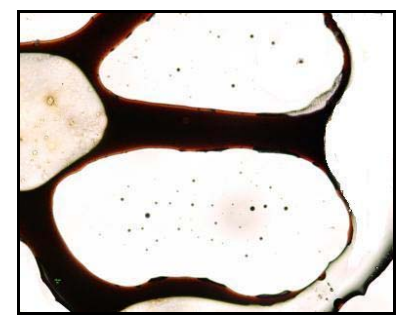

(d)
Figure 1. Pictures of one location of micromodel at four stages of oil displacement process. Oil phase: heavy oil, $\mathrm{Na}_{2} \mathrm{CO}_{3}$ concentration in alkaline slug: $0.20 \mathrm{wt} \%, \mathrm{Mg}^{2+}$ concentration in water: $100 \mathrm{mg} / \mathrm{L}$. (a) After water flooding; (b) after alkaline flooding; (c) 50 hours after alkaline flooding; (d) 150 hours after alkaline flooding. 


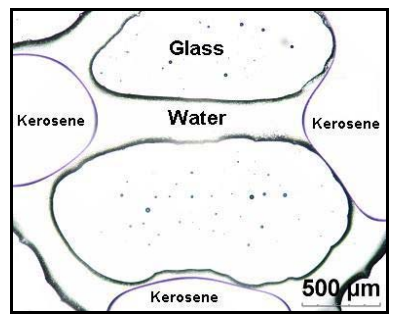

(a)

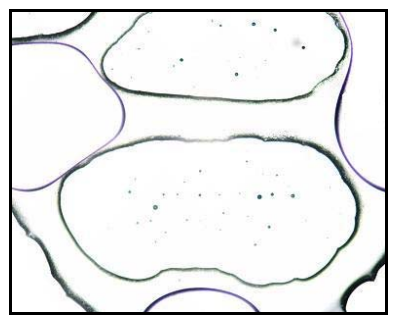

(c)

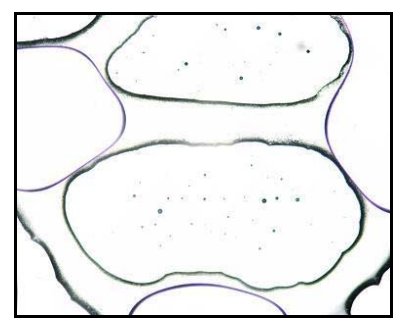

(b)

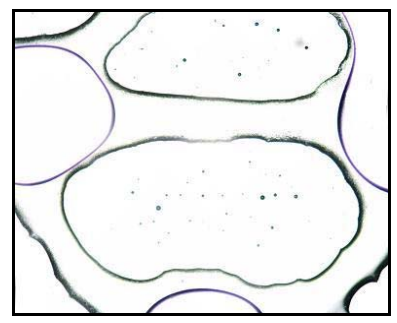

(d)
Figure 2. Pictures of one location of micromodel at four stages of oil displacement process. Oil phase: kerosene, $\mathrm{Na}_{2} \mathrm{CO}_{3}$ concentration in alkaline slug: $0.20 \mathrm{wt} \%, \mathrm{Mg}^{2+}$ concentration in water: $100 \mathrm{mg} / \mathrm{L}$. (a) After water flooding; (b) after alkaline flooding; (c) 50 hours after alkaline flooding; (d) 150 hours after alkaline flooding.

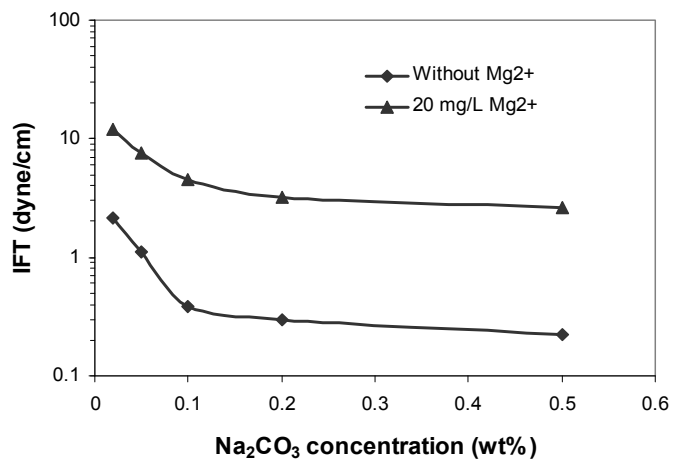

Figure 3. Interfacial tensions of heavy oil/water as a function of $\mathrm{Na}_{2} \mathrm{CO}_{3}$ concentration for cases of without and with $20 \mathrm{mg} / \mathrm{L} \mathrm{Mg}^{2+}$ in the water phase. $\mathrm{Na}_{2} \mathrm{CO}_{3}$ concentration: $0.20 \mathrm{wt} \%$.

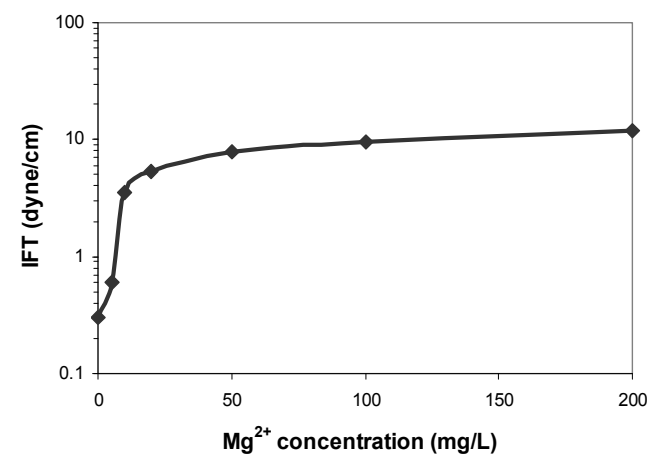

Figure 4. Interfacial tensions of heavy oil/water as a function of $\mathrm{Mg}^{2+}$ concentration. $\mathrm{Na}_{2} \mathrm{CO}_{3}$ concentration: $0.20 \mathrm{wt} \%$. measured and are shown in Figure 5. The system without $\mathrm{Mg}^{2+}$ exhibited dynamic IFT behavior and the other two systems with $\mathrm{Mg}^{2+}$ did not show the dynamic behavior within the measurement error. This indicates that the magnesium soaps were rapidly formed at the oil/water interface by magnesium ion binding.

\subsubsection{Partition of Organic Acids into Water Phase}

When organic acids in the oil phase are ionized in alkaline condition, they become more hydrophilic and capable to partition into water phase. In the water phase, they will have opportunities to contact, attach to and change the wettability of the sand surface. The presence of $\mathrm{Na}_{2} \mathrm{CO}_{3}$ and/or $\mathrm{Mg}^{2+}$ can affect the partitioning of the ionized organic acids and change the surface tension of the water phase. Investigating the surface tension of water can provide useful information on the partitioning of ionized organic acids.

Surface tensions of water samples of Series A and B were measured to investigate the effect of $\mathrm{Na}_{2} \mathrm{CO}_{3}$ and $\mathrm{Mg}^{2+}$ on partitioning of the acids into the water phase. The results are shown in Figure 6. For Series A (without $\left.\mathrm{Mg}^{2+}\right)$, surface tension decreased with $\mathrm{Na}_{2} \mathrm{CO}_{3}$ concentration. Surface tension was reduced to approximately 47

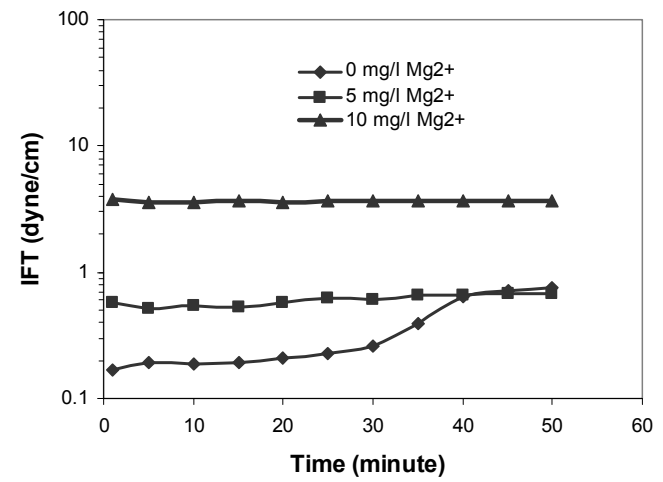

Figure 5. Dynamic interfacial tensions of heavy oil/water with different $\mathrm{Mg}^{2+}$ concentrations. $\mathrm{Na}_{2} \mathrm{CO}_{3}$ concentration: $0.20 \mathrm{wt} \%$.

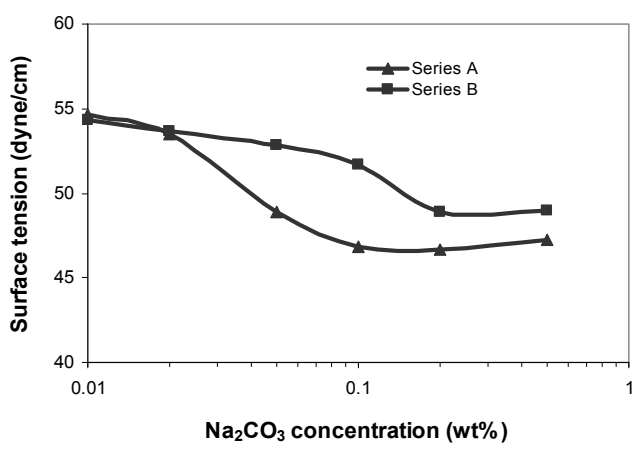

Figure 6. Surface tensions of equilibrium water phase as a function of $\mathrm{Na}_{2} \mathrm{CO}_{3}$ concentration. Oil/water ratio: 1/1, Series A: no $\mathrm{Mg}^{2+}$, Series B: $100 \mathrm{mg} / \mathrm{L} \mathrm{Mg}^{2+}$ in equilibrium brine. 
dyne/cm at $0.10 \mathrm{wt} \% \mathrm{Na}_{2} \mathrm{CO}_{3}$. This is the result of the formation of ionized organic acids and their partitioning into the water phase. These ionized organic acids in the water phase could not be detected with the two-phase titration method [17], indicating that only little of ionized organic acids were in the water phase. For Series B, containing $100 \mathrm{mg} / \mathrm{L} \mathrm{Mg}^{2+}$ in the equilibrium water phase, surface tension was higher than that of Series A at $\mathrm{Na}_{2} \mathrm{CO}_{3}$ concentrations higher than $0.02 \mathrm{wt} \%$. This is because the ion binding that deactivated the surface activity of the ionized organic acids in the water phase.

The surface tension of $1.0 \mathrm{wt} \% \mathrm{NaCl}$ brine was measured to be 73.0 dyne $/ \mathrm{cm}$. After $1.0 \mathrm{wt} \% \mathrm{NaCl}$ brine (without $\mathrm{Na}_{2} \mathrm{CO}_{3}$ or $\mathrm{Mg}^{2+}$ ) was equilibrated with the heavy oil $($ oil $/$ water volume ratio $=1: 1)$, no further reduction in surface tension of the water phase was observed within the experimental error. This suggests that no organic acids in the oil phase partitioned into the water phase. This behavior can be explained by the fact that organic acids in the oil phase were not ionized and were more hydrophobic. If the organic acids in the oil do not partition into the water phase, there will be no adsorption of organic acids on the surface of sand which is water-wet and covered with water. This is why the sand surface remained strongly water-wet in Test 1 listed in Table 2.

\subsubsection{Adsorption of lonized Organic Acids on Sand Surface}

In a heavy oil/brine/sand system, the adsorption of ionized acid onto sand surface affects hydration forces, making the sand surface more hydrophobic or more oil-wet [2]. In order to investigate the effect of the ionized organic acids on sand surface wettability, sand surface compositions were analyzed for five sand samples, one of which was the original sand. The other four samples, labeled S1, S2, S3 and S4, were equilibrated with water phase of different chemical compositions before surface composition analysis as follows: the water phase with $0.02 \mathrm{wt} \% \mathrm{Na}_{2} \mathrm{CO}_{3}$ in Series A was used for $\mathrm{S} 1$; the water phase with $0.02 \mathrm{wt} \% \mathrm{Na}_{2} \mathrm{CO}_{3}$ and $100 \mathrm{mg} / \mathrm{L} \mathrm{Mg}^{2+}$ in Series B was used for S2; the water phase with 0.5 wt $\% \mathrm{Na}_{2} \mathrm{CO}_{3}$ in Series A was used for S3; and the water phase with $0.5 \mathrm{wt} \% \mathrm{Na}_{2} \mathrm{CO}_{3}$ and $100 \mathrm{mg} / \mathrm{L} \mathrm{Mg}^{2+}$ in Series $\mathrm{C}$ was used for $\mathrm{S} 4$. For the above four sand samples, only the wettability of sand sample S4 changed from water-wet to oil-wet.

Seven elements were analyzed and the results are shown in Table 4. The change in the element percentage on the sand surface of samples S1-S4 was the indication of the adsorbed substances. The adsorption of ionized organic acids and $\mathrm{Na}_{2} \mathrm{CO}_{3}$ changed the percentage of carbon $(\mathrm{C})$ and oxygen $(\mathrm{O})$ while the adsorption of $\mathrm{NaCl}$ and $\mathrm{MgCl}_{2}$ from water phase increased the percentage of chloride $(\mathrm{Cl})$, sodium $(\mathrm{Na})$, and magnesium $(\mathrm{Mg})$.

The mole ratio of $\mathrm{C} / \mathrm{O}$ on the sand surface is also listed in Table 4. The $\mathrm{C} / \mathrm{O}$ mole ratio of the original sand was 0.40 and it increased from Samples S1 to S4. There are two sources for $\mathrm{C} / \mathrm{O}$ ratio change on sand surface: adsorbed $\mathrm{Na}_{2} \mathrm{CO}_{3}$ and ionized organic acids. The $\mathrm{C} / \mathrm{O}$ mole ratio for the compound of $\mathrm{Na}_{2} \mathrm{CO}_{3}$ is $33 \%$ which is lower than that of the original sand, showing that $\mathrm{Na}_{2} \mathrm{CO}_{3}$ adsorption on the sand surface from a water solution lowers the $\mathrm{C} / \mathrm{O}$ mole ratio. The ionized organic acids are polar compounds with a high molecular weight and a long organic carbon chain. Because of that, they are expected to have a much higher $\mathrm{C} / \mathrm{O}$ mole ratio $[4$, 12]. The adsorption of organic compounds on sand surface will provide more carbons. It is believed that the high carbon content and high $\mathrm{C} / \mathrm{O}$ mole ratio on sand surface for S1 to S4 are the result of the adsorption of ionized organic acids on the sand surface.

When a higher $\mathrm{Na}_{2} \mathrm{CO}_{3}$ concentration is applied in the water phase that is in contact with the oil phase, more organic acids will be ionized. Some of the ionized acids will subsequently partition into water, and adsorb onto the sand surface. The adsorption of ionized organic acids on sand surface is the reason for the higher $\mathrm{C} / \mathrm{O}$ mole ratio in Sample $\mathrm{S} 3\left(0.5 \mathrm{wt} \% \mathrm{Na}_{2} \mathrm{CO}_{3}\right)$ than in Sample S1 $\left(0.02 \mathrm{wt} \% \mathrm{Na}_{2} \mathrm{CO}_{3}\right)$. Table 4 shows that Sample $\mathrm{S} 4$ has a much higher $\mathrm{C} / \mathrm{O}$ mole ratio than Sample S3, indicating that much more ionized organic acids attached on the sand surface for Sample S4 than for Sample S3. There was $100 \mathrm{mg} / \mathrm{L} \mathrm{Mg}^{2+}$ in water phase for Sample S4 and no $\mathrm{Mg}^{2+}$ for Sample S3. The presence of $\mathrm{Mg}^{2+}$ increased the adsorption of ionized organic acids onto the sand surface. This indicates that wettability alteration of S4 is caused by the magnesium binding mechanism in the heavy oil/brine/sand system. Through the ion binding of $\mathrm{Mg}^{2+}$, more ionized organic acids in the aqueous phase attached to the sand surface. The hydrophobic tail of the surfactant on sand surface was more easily contacted by oil. The hydration forces became unfavorable for sustaining the water film between the oil and sand surface. It was concluded from the previous work [15] that the

Table 4. Sand surface element analysis (mole percent) and mole ratio of $\mathrm{C} / \mathrm{O}$.

\begin{tabular}{|c|c|c|c|c|c|c|c|c|}
\hline Element & $\mathrm{C}$ & $\mathrm{O}$ & $\mathrm{Cl}$ & $\mathrm{Si}$ & $\mathrm{Al}$ & $\mathrm{Na}$ & $\mathrm{Mg}$ & $\mathrm{C} / \mathrm{O}$ \\
\hline Original sand & 20.9 & 51.0 & $\mathrm{~N} / \mathrm{D}$ & 18.7 & 7.4 & 0.5 & $\mathrm{~N} / \mathrm{D}^{*}$ & 0.40 \\
\hline S 1 & 24.4 & 45.8 & 0.8 & 18.8 & 7.7 & 2.2 & N/D & 0.41 \\
\hline S 2 & 29.3 & 43.4 & 0.5 & 16.8 & 6.9 & 1.1 & 1.6 & 0.68 \\
\hline S 4 & 63.6 & 26.3 & 0.2 & 5.8 & 2.0 & 1.2 & 0.9 & 2.42 \\
\hline
\end{tabular}

* N/D-not detectable 
negative charges at both the oil/water and water/sand interfaces were reduced by the $\mathrm{Mg}^{2+}$ ion binding, weakening the repulsive forces between the two interfaces. The changes of both electrostatic forces and hydration forces contributed to the wettability alteration in the heavy oil/brine/sand system.

\section{CONCLUSIONS}

In this study, the mechanism of wettability alteration in a heavy oil/alkaline solution/sand system was investigated by analyzing the hydration forces, which revealed the following conclusions.

The presence of either $\mathrm{Na}_{2} \mathrm{CO}_{3}$ or $\mathrm{Mg}^{2+}$ alone in water could not induce wettability alteration. When water contained both $\mathrm{Na}_{2} \mathrm{CO}_{3}$ and $\mathrm{Mg}^{2+}$, wettability of the solid could be altered from water-wet to preferential oil-wet. Wettability of sand was altered from water-wet to preferential oil-wet by the $\mathrm{Mg}^{2+}$ ion binding mechanism. Under alkaline conditions, magnesium concentration of $\sim 50 \mathrm{mg} / \mathrm{L}$ could cause wettability alteration.

The heavy oil-water interfacial tension was greatly increased due to the combination of $\mathrm{Mg}^{2+}$ and the ionized organic acids at the oil/water interface. The analysis of sand surface composition showed significant increase in carbon content and $\mathrm{C} / \mathrm{O}$ ratio in sand top surface layer due to the adsorption of magnesium soap of the organic acids. These results are consistent with the reduction in surface charges at both the oil/water and water-sand interfaces obtained in a previous study. The magnesium ion binding reduced both electrostatic and hydration forces at the oil/water and water/sand interfaces and caused wettability alteration of sand surface.

Water phase surface tension data showed that the ionized organic acids can partition into the water phase. Through the $\mathrm{Mg}^{2+}$ ion binding, the ionized organic acids in the aqueous phase attached to the sand surface. The attachment of the organic acids on the sand surface decreased the hydration forces, making the sand surface more oil-wet.

\section{AKNOWLEDGEMENTS}

Acknowledgment is extended to the Petroleum Technology Research Centre (PTRC), Murphy Oil Company Ltd., the Natural Sciences and Engineering Research Council (NSERC) of Canada, and the Canada Foundation for Innovation (CFI) for their financial support for this work. The authors wish to express their thanks to Murphy Oil Company Ltd. for providing the oil and brine samples.

\section{REFERENCES}

[1] Dullien, F.A.L. (1992) Porous media - fluid transport and pore structure, 2nd Edition. Academic Press, San Diego.

[2] Hirasaki, G.L. (1991) Wettability: Fundamentals and surface forces. Society of Petroleum Engineering Formation and Evaluation, 6(2), 217-226.

[3] Liu, K., Eadington, P. and Coghlan, D. (2003) Fluorescence evidence of polar hydrocarbon interaction on mineral surfaces and implications to alteration of reservoir wettability. Journal of Petroleum Science and Engineering, 39(3-4), 275-285.

[4] Dubey, S.T. and Waxman, M.H. (1991) Asphaltenes adsorption and desorption from mineral surfaces. Society of Petroleum Engineering Research, 6(1), 389-395.

[5] Croker, M.E. and Marchin, L.M. (1988) Wettability and adsorption characteristics of crude oil asphaltenes and polar fractions. Journal of Petroleum Technology, 40(4), 470-474.

[6] Morrow, N.R., Cram, P.J. and McCaffery, F.G. (1973) Displacement studies in dolomite with wettability control by octanoic acid. Society of Petroleum Engineering Journal, 13(4), 221-232.

[7] Collins, S.H. and Melrose, J.C. (1983) Adsorption of asphaltenes and water on reservoir rock minerals. Proceedings of the SPE International Symposium on Oilfield and Geothermal Chemistry, 11800, Denver.

[8] Kaminsky, R. and Radke, C.J. (1998) Water films, asphaltenes, and wettablity alteration. SPE/DOE Symposium on Improved Oil Recovery, 39087, Tulsa.

[9] Kowalewski, E., Holt, T. and Torsaeter, O. (2002) Wettability alterations due to an oil additive. Journal of Petroleum Sciences and Engineering, 33(1-3), 19-28.

[10] Ashayer, R., Grattoni, C.A. and Luckham, P.F. (2000) Wettability changes during surfactant flooding. 6th International Symposium on Evaluation of Reservoir Wettability and its Effect on Oil Recovery, Socotrro.

[11] Buckley, J.S., Liu, Y. and Monsterleet, S. (1998) Mechanisms of wetting alteration by crude oils. Society of Petroleum Engineering Journal, 3(1), 54-61.

[12] Cooke, Jr.C.E., William, R.E. and Kolodzie, P.A. (1974) Oil recovery by alkaline waterflooding. Journal of Petroleum Technology, 26(12), 1365-1374.

[13] Miller, K.A. (2005) State of the art of western Canadian heavy oil water flood technology. Proceedings of Petroleum Society's 6th International Petroleum Conference (56th Annual Technical Meeting), 2005-251, Calgary.

[14] Ma, S., Dong, M., Li, Z. and Shirif, E. (2007) Evaluation of effectiveness of chemical flooding using heterogeneous sandpack flood test. Journal of Petroleum Science and Engineering, 55(3-4), 219-228.

[15] Liu, Q., Dong, M., Asghari, K. and Tu, Y. (2007) Wettability alteration by magnesium ion binding in heavy $\mathrm{oil} / \mathrm{brine} / \mathrm{chemical} /$ sand systems-Analysis of electrostatic forces. Journal of Petroleum Science and Engineering, 59(1-2), 147-156.

[16] Dong, M., Foraie, J., Huang, S. and Chatzis, I. (2005) Analysis of immiscible water-alternating-gas (WAG) injection using micromodel. Journal Canadian Petroleum Technology, 44(2), 17-25.

[17] ASTM (1989), Standard test method for synthetic anionic ingredient by cationic titration. Annual Book of ASTM Standards, American Society for Testing and Materials, West Conshohocken, 15(4), 320-323 